\title{
Entre o cárcere e a liberdade: a representação da mulher por Andradina de Oliveira
}

O perdão. 2. ed.

OLIVEIRA, Andradina de.

Organização: Rita Terezinha Schmidt. Fixação do texto e notas explicativas: Rosane Saint-Denis Salomoni e Anselmo Peres Alós.

Florianópolis: Editora Mulheres, 2010. $310 \mathrm{p}$.

Resgatar vozes que foram silenciadas ao longo de anos sem motivos justificáveis é papel não somente do historiador ou do sociólogo, mas também do crítico literário. Por isso, o texto literário funciona como propulsor de discussões sobre gênero e classe social, entre tantos outros vetores de subjetivação.' Já no início do século XX, Andradina de Oliveira, autora de O perdão, ousou debater temáticas como estas que, se hoje já não geram tanta polêmica, na época produziam bastante desconforto. Portanto, não é surpreendente que $O$ perdão tenha ficado à margem da historiografia literária nacional, de acordo com Lúcia Maia, em um extenso estudo sobre Andradina de Oliveira:

O perdão se constitui em uma narrativa que não foi reconhecida na época de sua publicação, e por se tratar de uma escritura feminina considerada "menor" pela crítica contemporânea a ela, ficou ausente de qualquer referência nos jornais da época, a exemplo de tantas outras. Entretanto, ainda que não seja possível recuperar uma inclusão que não houve na época, é sim possível enriquecer o presente e o futuro com narrativas que se constituíram às margens do discurso oficial e não obtiveram legitimação a despeito do seu valor intrínseco, como é o caso de $O$ perdão. A obra traz subsídios preciosos tanto do ponto de vista literário quanto histórico, e merece um estudo apropriado para que possa integrar o acervo cultural do período. ${ }^{2}$

Contudo, se Andradina de Oliveira procurava visibilizar as vozes perdidas no escuro da história do início do século XX, o mesmo não se pode dizer da própria autora, que não obteve o devido reconhecimento de sua obra em seu próprio tempo. Talvez pelo desconforto originado pelas temáticas tratadas no romance, ou talvez pelo fato de ser uma mulher letrada, dona de um jornal, inserida no contexto da sociedade masculinista e patriarcal de Porto Alegre de final do século XIX e início de século XX, Andradina de Oliveira tenha tido, assim como muitas mulheres que escreviam nesse período, sua voz e seus escritos olvidados pela historiografia literária oficial. ${ }^{3}$ Apenas recentemente Andradina de Oliveira teve sua obra reconhecida, resultado de um esforço da crítica contemporânea de resgatar bons escritores marginalizados pelo cânone, e mesmo pelos seus leitores coetâneos.

Andradina de Oliveira (1864-1935), líder feminista, conferencista, biógrafa, teatróloga, escritora de romances e contos, educadora e jornalista porto-alegrense, escreveu textos como A mulher rio-grandense (biografias, 1907), Cruz de pérolas (contos, 1908), Contos de natal (contos infantis, 1908), O perdão (romance, 1910), Divórcio? (romance, 1912) e O abismo (romance, 1912). Além disso, de acordo com Rosa Cristina Hood Gautério, a escritora foi 
fundadora do jornal Escrínio, em Bagé (RS), depois estabelecido definitivamente em Porto Alegre. ${ }^{4} \mathrm{O}$ lema do jornal já indica um dos rumos fundamentais dos textos da escritora: "pela mulher". É precisamente a luta pelos direitos da mulher o cerne da produção intelectual de Andradina de Oliveira, sempre abordando temas polêmicos como o casamento, o divórcio e o sufrágio feminino.

Em O perdão, a luta pela autonomia da mulher perante o homem, a discussão do papel da mulher em uma sociedade patriarcal e machista e a reflexão sobre o papel da mulher como objeto representado no discurso literário são temáticas de extrema importância. Entretanto, é possível perceber, no romance, reflexões que vão além das questões de gênero. Andradina de Oliveira aborda com maestria as diferenças entre classes sociais, questiona as relações amorosas em uma sociedade de aparências, problematiza a hipocrisia dos valores familiares da época, e ainda encontra lugar para pertinentes discussões metaficcionais.

Aliás, essas discussões metaficcionais são mais interessantes ainda por serem uma prática incomum em textos do início do século XX. Nesse sentido, as reflexões críticas da narradora sobre - estilo e temáticas dos textos românticos e naturalistas ao final de $O$ perdão, por exemplo, são fundamentais porque refletem, de certo modo, o tipo de texto produzido no decorrer do romance e explicam o texto literário, ressaltando seu caráter inquestionavelmente ficcional, como é possível perceber no seguinte excerto:

- Pois eu, - acudiu o Lodônio, o sumidinho, já não penso assim. O sentimentalismo, o lirismo são eternos, porque são o verdadeiro alicerce da natureza humana e a fonte de toda a arte. Se é pieguice, as grandes obras imortais são todas piegas. Olhem, o caso desta moça com um pouco de colorido, de fantasia, que bela elegia sentimental não daria, hein? "Morrer de amor!", que esplêndido tema!

- Qual! - voltou o Nazário. - Você, sempre há de ser um casimiriano, seu Lodônio. O caso desta moça só pode ser hoje tolerado, em literatura, como um estudo de fisiologia, fazendo dela uma doente, com os nervos bambos pela embriaguez de uma luxúria espiritual; a volúpia da música, a despedaçarIhe o organismo em reações histéricas... Só assim! (p. 295).

É possível perceber que, em um dos últimos capítulos do texto, foram criadas personagens exclusivamente para comentar 0 desenlace trágico da trama e refletir metaficionalmente 0 que é facilmente apreendido através de uma interpretação dos trechos em que aparecem. No trecho acima, nota-se que a personagem faz uma apreciação do evento - a morte de Celeste, ocasionada pelo amor que sentia por Armando, o qual, por sua vez, fugiu com Estela, irmã de Celeste - como possível objeto de literatura, quando, ao fim e ao cabo, tal evento é realmente um objeto literário. As personagens conversam sobre dois possíveis tipos de tratamento literário do evento, um voltado ao desenvolvimento do lirismo e do sentimentalismo e outro voltado ao desenvolvimento da personalidade feminina patologicamente marcada. O interessante, nesse caso, é que ambos os tratamentos estão presentes em $O$ perdão. Portanto, o final do romance funciona quase como uma explicação dos artifícios e recursos utilizados pelo próprio texto ficcional de Andradina de Oliveira.

Cem anos após o lançamento da primeira edição de $O$ perdão, foi lançada uma edição comemorativa do romance de Andradina de Oliveira. O texto foi atualizado ortograficamente por Anselmo Peres Alós e Rosane Saint-Denis Salomoni, responsáveis também pela redação das notas explicativas. Ressalta-se que foram mantidas as especificidades do texto e as marcas autorais, apesar da necessária atualização de alguns aspectos, como o uso de iniciais minúsculas após pontuação final. A edição vem acompanhada de um texto introdutório de Rita Terezinha Schmidt, ${ }^{5}$ que, além de indicar aspectos biográficos importantes e contextualizar o período no qual foi publicada a obra, realiza uma análise minuciosa do romance, fundamental para o entendimento pleno do lugar ocupado por Andradina de Oliveira na ficção sul-riograndense, e mesmo no cenário nacional do início do século XX.

O fato de $O$ perdão ser um texto do início do século XX deixado na obscuridade poderia assustar aqueles que esperam obter uma leitura prazerosa. Contudo, o enredo do romance cativa imediatamente o leitor. Ambientado na Porto Alegre do início do século XX, O perdão trata da história de adultério de Estela, uma das filhas da tradicional família chefiada pelo estancieiro Leonardo. No início do romance, é apresentado o cotidiano da família de Estela, a trajetória particular de cada personagem, suas relações com o espaço e com os indivíduos subalternizados; na segunda parte, a narrativa centra-se no relacionamento extraconjugal de Estela com Armando, sobrinho de seu marido.

A família de Estela é tipicamente aristocrática, influenciada pela forma de pensar, agir e vestir à europeia. Leonardo, o patriarca respeitado 
e venerado pelas filhas e pela esposa, é um rico estanceiro, ex-estudante de Direito, mas que não exerceu a profissão. Leonardo casou-se com Paula, uma moça pobre, porém com excelentes habilidades domésticas e musicais e de incomum beleza. Os frutos desse relacionamento são apresentados como seres encantadores, adoráveis, belos e misteriosos. A narradora, inclusive, sintetiza a personalidade das filhas do casal com um adjetivo para cada: a "fascinante Estela", a "angelical Celeste" e a "sedutora Lucia" (p. 40). Na segunda parte da história, Estela, anteriormente caracterizada pelas personagens como sedutora e diabólica, acaba seduzida por Armando, um homem belo, viril, jovem, de ideias fortes, o exato oposto de Jorge, um homem de elegância principesca, rico, amoroso, bom moço, porém sem graça, levemente efeminado, recatado e extremamente tímido.

A forma como é tecido o universo narrativo é um dos aspectos mais expressivos do romance. A narradora do romance é onisciente, mas mantém uma posição de relativa neutralidade em relação aos eventos narrados e às personagens. Os comentários, apreciações e juízos de valor são feitos, principalmente, pelas personagens, através do confronto de pontos de vista originado pela mobilidade da focalização. No início do romance, a narradora limita-se a introduzir o enredo, ambientando espacialmente as personagens e apresentando suas características principais, fazendo com que as personagens contem a história daquela família através do que observam ou lembram. Isso é fundamental, na medida em que provoca choques entre as visões dos diferentes membros da família, funcionando então em conjunto com a apresentação das características físicas e psicológicas das personagens pela narradora, uma vez que a focalização interna pode servir para revelar o íntimo das personagens e suas percepções sobre o mundo que as cerca. Ademais, conferir importância às diferentes percepções de personagens subalternas, incluindo as mulheres e os trabalhadores das classes subalternizadas (como Birutinha), vai ao encontro da postura da autora de dar voz aos que foram silenciados, promovendo a pluralidade de pontos de vista dentro do universo ficcional.

Depois de apresentar o cotidiano da família de Estela, a narradora apressa a história, promovendo uma sumarização de três anos e passando a manter o foco na vida conjugal de Estela. Na seguinte passagem, em que Estela e Armando já estão dentro do trem depois da fuga, percebe-se a importância desse tipo de narração para o romance, como a capacidade do narrador de perscrutar o íntimo das personagens, demonstrando que as duas personagens estavam dissonantes em função de um mesmo evento:

Uma estrepitosa salva de palmas festejava o talento de Armando num trecho dificílimo de Wagner. O moço, cantando, tinha só um fito: acordar na alma da amante aquela mesmo alucinadora paixão que os perdera. A sua voz de barítono, poderosamente arrebatadora, tinha um timbre impressionante, uma doçura veludosa e quente.

Estela ergueu-se trêmula, desvairada. Ah! Ele cantava! Podia cantar enquanto ela se estorcia de desespero! Cruel! Monstro que a arrojara ali naquele horrendo repúdio que ia ser sua vida, se a morte não pusera $o$ ansiado remate ( $p$. 239).

Como pode ser percebido, Armando tentava seduzir Estela para recuperar o irrecuperável, isto é, a paixão arrebatadora. No entanto, essa atitude somente resulta em mais desgosto e infelicidade para Estela. Logo, confrontar as visões das personagens é um movimento essencial do texto na medida em que torna a história mais dinâmica e revela os sentimentos e preconceitos tanto do homem quanto da mulher em relação ao amor e ao adultério. Por fim, a onisciência da narradora e o confronto das diferentes visões também são essenciais, porque somente através disso é possível chegar a conclusões acerca do estado de saúde de Estela. Enquanto revela os pensamentos de Estela e as reações de Armando às atitudes dela, a narradora vai construindo paulatinamente com o leitor a imagem de uma mulher perdida pelo amor e pelo medo originado nos entraves sociais, uma mulher dividida entre liberdade e cerceamento, entre pensar e agir, 0 que resulta em depressão, histeria e desejo suicida.

Assim, o papel de Estela no romance vai além de promover reflexões sobre o adultério. Estela, e seu trágico percurso ao longo do romance, trazem à tona discussões sobre o lugar da mulher em uma sociedade patriarcal e machisła, questão que emerge sintetizada na fala de Tia Zina: "a mulher, depois de casada, morre para o mundo. É tratar dos filhos, do marido e nada mais" (p. 142). Apesar da vontade de agir como a sociedade esperava, respeitando o marido, os filhos, o pai, o desejo tomou conta de Estela de forma tão irremediável que a personagem não teve outra opção a não ser lutar contra os entraves sociais que delimitavam 
as atitudes da mulher na época e refletir de maneira crítica sobre a problemática feminina: "para todos os crimes do homem há atenuantes, para os erros da mulher só agravantes" (p. 240).

Mesmo resultando em doença e culpa, a atitude de Estela é mobilizada como comportamento exemplar para demonstrar que as mulheres também são assombradas por desejos, anseios e necessidades, os quais nem sempre estavam restritos ao que se esperava de uma mulher nos primórdios do século XX. Em função disso, Estela funciona muito mais como contraponto ao despotismo de uma sociedade masculinista do que a sua mãe, Paula, que no romance demonstrase favorável ao que chama de "emancipação da mulher", mas age apenas dentro dos limites que cercavam as atitudes femininas:

- Ora deixe-se de tolices, tia Zina! Você nem parece que está no século $X X$, no reinado da emancipação da mulher. Longe vai a nossa escravidão! Longe vão os absurdos preconceitos! Fique certa, tia Zina, que a mulher pode muito bem cumprir as suas obrigações sem ficar criando bolor em casa, deixando inchar as pernas e engrossar a cinta.

- São modos de ver, Paula, são modos de ver. Não digo que não se saia... Pode-se sair... todos os dias até... ir à igreja... à missa... a oração nos conforta... nos dá força... (p. 142143).

Como se percebe no trecho citado, Paula apresenta uma posição em prol dos direitos das mulheres, em oposição à Tia Zina, que representa as mulheres que assimilavam e propagavam o discurso machista, não vendo com bons olhos a liberdade feminina. Paula, ao longo do romance, além de ser apresentada como um ser apático, tomando voz em poucas falas e participando de poucas cenas, fica sempre ao jugo do marido e da sociedade. Nesse sentido, na continuação do diálogo entre Tia Zina e Paula acerca da "emancipação da mulher", é sintomática a fala de Leonardo, que encerra a discussão inserindo as reflexões da esposa no campo semântico infantil: "Leonardo desatou a rir batendo nas coxas: - Essa Paula! É mesmo levada, Tia Zina!" (p. 143).

Enquanto Paula é a porta-voz do discurso feminista, Estela, que procurava se espelhar na relação dos pais e tentava corresponder ao que a sociedade esperava de uma mulher casada e mãe, acaba funcionando exatamente como a personagem instauradora de uma mudança de atitude. Estela apaixona-se por outro homem, relaciona-se com ele, foge com esse outro homem, abandona família e filhos em busca da felicidade e reflete criticamente sobre suas atitudes, sobre as atitudes de Armando, sobre a sua situação naquela sociedade depois dos últimos eventos. Com isso, entende-se que a liberdade feminina não era apenas uma luta retórica, mas sim uma necessidade, já que uma personagem que não desejava afrontar os cárceres femininos acaba demonstrando uma intensa vocação para ser livre. ${ }^{6}$

Nesse sentido, uma personagem sem grande destaque na trama revela-se fundamental para mostrar o ridículo inerente ao imaginário patriarcal da sociedade porto-alegrense da época: Birutinha. A personagem aparece poucas vezes na história e, quando aparece, provoca constrangimentos e vergonha para a família de Estela, pois, além de falar tudo que as personagens prefeririam manter em silêncio, Birutinha é feia, pobre, asquerosa, velha e faminta. Birutinha é uma prima distante de Paula. Quando jovem, era linda, rica, possuía muitos escravos e pretendentes. Porém, a má sorte destruiu a vida da personagem: os escravos fugiram, os irmãos morreram, o noivo foi assassinado por engano. Sem homens para auxiliá-la a viver, sem escravos e sem dinheiro para luxos, restou para Birutinha somente um caminho: a miséria física e financeira. A personagem sinaliza as dificuldades enfrentadas pelas mulheres no Rio Grande do Sul no final do século XIX e inícios do XXI. ${ }^{7}$ Birutinha aparece no romance, portanto, funcionando como uma crítica irônica, às avessas, apresentando a hipocrisia de uma sociedade retrógrada e conservadora, demonstrando que, sintomaticamente, para aquela sociedade, uma mulher sem marido ou homem da família e sem dinheiro simplesmente não pode ter uma existência segura.

\section{Notas}

${ }^{1}$ Anselmo Peres ALÓS, 201 1a; 2012a; 2012 b.

2 MAIA, 2010, p. 12.

${ }^{3}$ ALÓS, 2011 b; $2011 \mathrm{c}$.

${ }^{4}$ GAUTÉRIO, 2013.

${ }^{5}$ SCHMIDT, 2010, p. 9-12.

${ }^{6}$ ALÓS, $2012 b$, p. 199.

${ }^{7}$ ALÓs, 2008, p. 691.

\section{Referências}

ALÓS, Anselmo Peres. "Um passo além: o resgate de escritoras brasileiras do século XIX". Revista Estudos Feministas, UFSC, v. 16, n. 2, p. 691-693, 2008.

"Gênero, epistemologia e performatividade: estratégias pedagógicas de subversão". Revista Estudos Feministas, UFSC, v. 19, n. 2, p. 421-449, 2011 a. 
. "Uma comunidade imaginada chamada nação". Letras \& Letras, UFU, v. 27, n. 2, p. 439-444, $2011 \mathrm{~b}$.

. "O estado da arte de um campo disciplinar assolado pelas crises do presente". Ipotesi, UFJF, v. 15 , n. 2 , p. 149-153, $2011 \mathrm{c}$.

. "A literatura comparada neste início de milênio: tendências e perspectivas". Ângulo, FATEA, v. 130, p. 7-12, 2012a.

."Literatura comparada ontem e hoje: campo epistemológico de ansiedades e incertezas". Organon, UFRGS, v. 27, n. 52, p. 17-42, 2012b.

GAUTÉRIO, Rosa Cristina Hood. Escrínio: a imprensa feminina sul-riograndense como produto cultural na construção da história das mulheres. Disponível em: <http:// ebooks.pucrs.br/edipucrs/Ebooks/Web/97885-397-0198-8/Trabalhos/89.pdf > . Acesso em: 2 mar. 2013.

MAIA, Lúcia Henriques. O perdão, de Andradina de Oliveira: romance urbano na belle époque rio-grandense. 2010. Dissertação (Mestrado em Estudos de Literatura) Programa de Pós-Graduação em Letras, Universidade Federal do Rio Grande do Sul, Porto Alegre. Orientadora: Rita Terezinha Schmidt.
OLIVEIRA, Andradina de. A mulher rio-grandense: escriptoras mortas. Porto Alegre: Americana, 1907. $1908 a$.

. Cruz de pérolas. Porto Alegre: Americana, . Contos de natal. Porto Alegre: Americana, 1908b. . O perdão. Porto Alegre: Americana, 1910. . Divórcio? Porto Alegre: Universal, 1912a. . O abismo. Porto Alegre: Universal, 1912b. . "Última noite de outono" (conto). In: CARVALHO, Nelly Rezende; KRUG, Guilhermina. Letras rio-grandenses. Porto Alegre: Globo: 1935. p. 159-161.

. "Àmargem do Guaíba" (poema). In: MACHADO, Antônio Carlos. Coletânea de poetas sul-riograndenses. Rio de Janeiro: Minerva, 1952. p. 160. $150 \mathrm{p}$.

Divórcio? 2. ed. Porto Alegre: ALFRS, 2007.

SCHMIDT, Rita Terezinha. "Introdução". OLIVEIRA, Andradina de. O perdão. 2. ed. Organização: Rita Terezinha Schmidt. Fixação do texto e notas explicativas: Rosane Saint-Denis Salomoni e Anselmo Peres Alós. Florianópolis: Editora Mulheres, 2010. p. 9-23.

Julian Bohrz Universidade Federal de Santa Maria 